\title{
Methodology for the Development of Search and Research Skills of Prospective Math Teachers in a Course on Mathematical Physics Equations
}

\author{
Bakhyt Sydykhov ${ }^{1 *}$, Serik Daiyrbekov ${ }^{2}$, Moldir Muratbekova ${ }^{3}$, Zhazira Issayeva ${ }^{3}$, \\ Meruyert Burkitbayeva ${ }^{3}$, Mehmet Kavakli ${ }^{3}$, Luiza Rizayeva 4 \\ ${ }^{1}$ Abai Kazakh National Pedagogical University, KAZAKHSTAN \\ 2 Syrdariya University, KAZAKHSTAN \\ ${ }^{3}$ Kh. Yasavi International Kazakh-Turkish University, KAZAKHSTAN \\ ${ }^{4}$ South Kazakhstan Pedagogical University, KAZAKHSTAN
}

Received 26 May 2017 - Revised 2 September 2017 • Accepted 25 September 2017

\begin{abstract}
This research proposes theoretical and methodological recommendations that would develop search and research skills applied by prospective math teachers while teaching a course on mathematical physics equations. The research findings include the firstever attempt to set up and solve the challenge of developing students' search and research skills when being taught a course on mathematical physics equations through a specially developed methodology. The authors propose a structural content model of search and research skills, and define the types of mathematical problems that facilitate the development of search and research skills used by prospective math teachers when teaching a course on mathematical physics equations.
\end{abstract}

Keywords: search and research skills, prospective math teachers, mathematical physics equation, methodology

\section{INTRODUCTION}

The relevance of this study stems from the fact that when doing a course on mathematical physics equations, most Math students encounter a number of logical challenges related to the very nature of this subject. This occurs due to the insufficient mastery of skills necessary for this type of learning. This results in a contradiction that has formed in students training: on the one hand, university staff should come up with the theoretical and methodological basis for managing the search and research activities of prospective math teachers when they take a course on in mathematical physics equations and the insufficiently developed theory, methodology and challenges related to this; on the other hand, prospective math teachers should be able to apply search and research skills not only when studying at university, but also in further work in education, which necessitates the use of productive methods of instruction.

The following research methods were used in this study: theoretical analysis of publications on philosophy, psychology and education; analysis of the university course content on mathematical physics equations and publications on the issues related to the research; conducting a pedagogical experiment, analysis and processing of experiment results and methods of mathematical statistics.

The practical relevance of this research includes the development, introduction, and testing of methodology aimed at mastering prospective math teachers' search and research skills in the mathematical physics equations course. The authors propose educational tools facilitating the development of search and research skills of prospective math teachers when they take a course of mathematical physics equations. The authors created an elective course "Methodology of managing students' search and research skills in the mathematical physics equations course" which acts as a link between students' theoretical knowledge and practical skills.

\footnotetext{
(C) Authors. Terms and conditions of Creative Commons Attribution 4.0 International (CC BY 4.0) apply. 


\section{Contribution of this paper to the literature}

- $\quad$ The proposed methodology aimed at developing search and research skills of prospective math teachers in the mathematical equations course can be used as a theoretical basis for further research in other math subjects.

- Knowledge in this subject can be used in mathematical modeling of applied and physical problems, when studying other math subjects, as well as form the basis for further research on certain topics in the mathematical physics equations course.

- The research equipped prospective teachers with math and methodological materials that they can use in their further work at school.

During a university course, students' academic activities gradually acquire some features of teacher's work their prospective occupation. To meet the requirements set for this job, students should take an active position from the beginning of their training, which is achieved by doing various research activities. After all, besides mastering the knowledge being taught, prospective teachers should be able to independently register, identify, set and solve fairly difficult tasks, apply the acquired knowledge in the most efficient way, think independently and develop their imagination. Therefore, learning content should include not only certain educational information, but also educational activities (skills).

Learning skills allow students to coordinate their work when doing academic assignments, and enable them to plan appropriate sequence of actions. However, schools and universities still do not pay due attention to the methods of skills development, in particular, skills required for search and research activities. These not only regulate students' activities at each stage of the creative work, but also represent a step towards the development of skills required for applying the obtained knowledge in various real-life situations and the skills of conducting research. Therefore, they should become a focus of attention and should be purposefully formed.

To date, there is practically no research devoted to methods of developing search and research skills in math subjects. Articles dealing with this issue consider only a few heuristic methods of solving this problem.

Having considered the things the mentioned above, we can conclude that despite a significant number of studies devoted to the considered problem, more attention should be paid to the basic dilemma, which implies finding ways to facilitate teaching mathematical physics equations with the purpose of developing students' search and research skills that improve their subject knowledge and the level of vocational training.

All of the above proves the relevance the research topic "Methodology of the development of search and research skills of prospective math teachers in the mathematical physics equations course".

\section{MATERIALS AND METHODS}

The main research methods include the study of laws and educational programs of the Republic of Kazakhstan and other countries, the works of Kazakhstan and international educators, philosophers and psychologists, regulatory documents of the Republic of Kazakhstan, materials of international scientific and practical conferences, and teaching experience of the researchers. The experiment was conducted in the South Kazakhstan State Pedagogical Institute, M. Auezov South Kazakhstan State University, Kh. Yasavi International Kazakh-Turkish University.

The research consisted of three stages:

At the first stage, the authors carried out a theoretical analysis of scientific, methodological, psychological and pedagogical papers concerning the theory and methodology of teaching mathematics. The researchers made observations, as well as conducted surveys and interviews with students and schoolchildren, participants of scientific and practical conferences; the conditions facilitating research skills development were identified, and the research problem was outlined. The authors formulated the goal, objectives and hypothesis of the study and proved the relevance of the research.

During the second stage, the key concepts and theoretical provisions of the study were examined and specified; observations were made on how well students acquired mathematical physics equations and their work in class; the authors created the model of search and research skills development and compiled complex problems on the mathematical physics equations used within this model.

The authors improved the methods of developing research skills of prospective math teachers in the mathematical physics equations course, developed the content of a special elective course for students, and conducted an experiment. 
At the third stage, the research findings were tested in university instruction; the forming experiment was organized and conducted, the results of the pedagogical experiment were summed up, the findings were processed, systematized and analyzed, conclusions were formulated, and the thesis was completed.

\section{RESULTS}

The issues of using problems in math teaching have been thoroughly explored. In their studies, J. Dinet, A. Chevalier, A. Tricot (2012), Amir Abdolhossini (2012), Masami Isoda (2010), M. Simon (2014), Zhanara M. Nurmukhamedova, Dilara M. Nurbaeva, Lyazzat D. Zhumalieva (2016), S. Rezat (2017), A. E. Abylkasymova (2016) and others noted that solving problems is an important tool for students acquiring mathematical knowledge and skills and is their main learning activity when studying mathematics.

The elective course "Methodology of managing students' search and research activities in a course on mathematical physics equations" is one of the key points in our research.

The elective course is based on the requirements established in the State Compulsory Standard of Higher Education of the Republic of Kazakhstan for bachelors of mathematics.

The implementation of the requirements implies setting the following tasks:

a) teaching students to use search and research skills of modern mathematical methods and models from the covered course;

b) developing students' search and research skills and a solid basis of theoretical knowledge, developing skills required for solving problems of the subject, raising the general level of their math knowledge;

c) developing search and research activities of prospective math teachers related to modeling and solving problems of mechanics and applied physics;

d) teaching search and research skills for self-study of educational and scientific papers.

The number of credits equaled 3, of which: lectures - 15, seminars - 30, students' individual work under teacher's supervision -45 , students' individual work -45 , with a total of 135 hours.

The course covers the following areas:

1. Mathematical physics equations

2. Hyperbolic equations

3. Parabolic equations

4. Elliptic equations

5. Special functions

6. Integro-differential equations.

The purpose of the course is to develop the following search and research skills of students:

- to master search and research skills required for solving partial differential equations that help to simulate, analyze and solve problems of applied physics;

- to master search and research skills required for solving mathematical physics equations and teaching students the skills of setting and solving specific problems;

- to understand the relationships and the content of certain concepts and statements of the theory of mathematical physics equations;

- to broaden their theoretical knowledge on modern mathematics problems when studying mathematical physics equations;

- to master search and research skills required for solving problems with partial differential equations that are used in mathematics, mathematical analysis and applied mathematics;

- to prepare for studying other mathematical methods and other math subjects;

- to independently obtain results, which would allow them to set up problems, put forward hypotheses, confirm or reject the formulated propositions.

- to develop logical and algorithmic thinking, independent planning skills, math knowledge and mathematical intuition necessary for further work when studying and solving mechanics, natural science and technology problems.

Having mastered the course, students should

\section{know:}

- current mathematical concepts, methods and models used in the analysis of partial differential equations;

- basic principles of research and methods for solving mathematical physics equations;

- interrelation, interdependence and mutual influence of concepts and methods of the course not only on each other, but also with other mathematical and physical subjects; 


\begin{tabular}{|c|c|}
\hline $\begin{array}{c}\text { Setting up } \\
\text { a problem }\end{array}$ & $\begin{array}{c}\text { Putting forward } \\
\text { a hypothesis }\end{array}$ \\
the hypothesis
\end{tabular}

Figure 1. The basic structure of search and research activities

\section{be able to:}

- to study and solve the main types of problems with partial differential equations using search and research skills;

- to solve problems of mechanics and applied physics using search and research skills;

- to analyze the behavior of partial differential equations, relying on the results obtained by using search and research skills.

In the work "Search and research activities of students in mathematics", V. A. Dalinger proposes a plan of the basic structure of research, which confirms the selection of the skills listed above (Dalinger, 2005, p.71). This selection is also determined by the main provisions of the problem-based learning theory which is the theoretical basis of our study. According to this theory, thinking is primarily a process of problem-solving (Figure 1).

As we go forward, we will refer to these three skills as the main search and research skills of prospective math teachers, and we will consider in greater detail the solutions to the problems of the elective course when developing these skills.

Analyzing the problems included in the course, primarily, notes the following: 1) problems on finding optimal conditions (problem on finding such a combination of the input parameters of the object that provides the optimal (minimum or maximum) value of the output parameter); 2) problems on the construction of interpolation formulas. When developing the problems used in the experiment, we also paid special attention to optimization problems (problems of finding the greatest/least values).

When planning and conducting a pedagogical experiment, we included various problems on experimentation which contributed to the development of one or more skills of students' search and research activities. Below, we would like to present some examples of such problems and consider which of the main skills of search and research activities should be developed there.

Let us describe the process of developing the main search and research skills of students when solving problems.

Problem 1.

1. Find the general solution of the following partial differential equation:

$$
v_{\xi \eta}-2 v_{\xi}+\frac{1}{2} \eta e^{\frac{1}{2} \xi+2 n}=0 .
$$

2. Find a solution that satisfies the Cauchy conditions:

$$
\begin{gathered}
u(x, y)=\left[f_{1}(y-\sin x-x)+f_{2}(y-\sin x+x)\right] e^{\frac{y-\sin x-x}{2}}, \\
\left.u\right|_{y=\sin x}=\cos x,\left.u_{y}\right|_{y=\sin x}=\sin x .
\end{gathered}
$$

3. Solve the Cauchy problem: $x u_{x x}-u_{y y}+\frac{1}{2} u_{x}=0$;

$$
\left.u\right|_{y=0}=x,\left.u_{y}\right|_{y=0}=0, x>0
$$

1) Using the method of characteristics, find the general solution of the partial differential equation.

2) Formulate a hypothesis using the Cauchy conditions, and find arbitrary functions contained in the general solution.

Setting up a problem

1. Bring the initial equation to the canonical form;

2. If necessary, further simplify the canonical form;

3. Integrate the equation for variables $\xi$ and $\eta$. Go back to variables $x$ and $y$.

Students are given this problem when studying the material of the section "Mathematical physics equations", the topic "The Cauchy problem. Problems with data on characteristics. Correct and incorrect problems. Solutions stability". In the beginning, the teacher notes that, as a rule, the class has not been given a clear definition of the Cauchy condition, arbitrary functions, and variables. For instance, the following problem is set to establish satisfying Cauchy conditions. In the course of the experiment, each student calculates the arbitrary functions contained in the solution using the Cauchy conditions (Muratbekova et al., 2014). 
Putting forward a hypothesis

Students quickly establish that 1) $A=x ; B=0 ; C=-1 ; B^{2}-A C=x$, i.e. equation (1) is a hyperbolic one. The characteristic equation has the form: $\frac{d y}{d x}=\mp \frac{1}{\sqrt{x}}$. The characteristics are the curves: $y=2 \sqrt{x}+C_{1}, y=-2 \sqrt{x}+C_{2}$.

Next, they obtain a change: $\xi=y+2 \sqrt{x}, \eta=y-2 \sqrt{x}$.

And bring equation (1) to the canonical form: $u_{\eta \xi}=0$.

2) Here, students' attention is drawn to the fact that when integrating, the canonical form of the equation must be written in the general solution: $u(x, y)=f_{1}(y+2 \sqrt{x})+f_{2}(y-2 \sqrt{x})$.

Proving the hypothesis

3) Finally, to find arbitrary functions contained in the solution (2), students use the Cauchy conditions and create the set of equations: $f_{1}(2 \sqrt{x})+f_{2}(-2 \sqrt{x})=x, f_{1}(2 \sqrt{x})+f_{2}^{\prime}(-2 \sqrt{x})=0$. In this set of equations they establish: $f_{1}(2 \sqrt{x})=$ $\frac{x}{2} ; f_{2}(-2 \sqrt{x})=\frac{x}{2}$. Established $f_{1}$ and $f_{2}$ are substituted in the general solution (2). Finally, students draw a conclusion that the solution of the Cauchy problem is

$$
u(x, y)=\frac{(y+2 \sqrt{x})^{2}}{4 * 2}+\frac{(y-2 \sqrt{x})^{2}}{4 * 2}=\frac{1}{8}\left(2 y^{2}+8 x\right)=\frac{y^{2}}{4}+x .
$$

Thus, students have solved the problem posed.

Problem 2.

Solving boundary value problems by the variables separation method. The Fourier method for elliptic equations in a rectangle, in a half-strip, in a ring, in a circle, outside the circle, in a circular sector.

1. To find the solution of the Laplace equation in a rectangle $0<x<a, 0<y<b$, if at the boundary of this polygon $u(x, y)$ takes on values:

$$
\left.u\right|_{x=0}=A \sin \frac{\pi y}{b} ;\left.u_{x}\right|_{x=a}=0 ;\left.u\right|_{y=0}=B \sin \frac{\pi x}{a} ;\left.u_{y}\right|_{y=b}=0 .
$$

2. To find the solution of the Laplace equation in a half-strip $0<x<\infty, 0<y<l$, if the boundary conditions have the form: $u(x, 0)=u(x, l)=0, u(0, y)=y(l-y), u(\infty, y)=0 ; u(x, y)=0, h>0$

Students are told that the solution of boundary value problems for the Laplace equation for domains (a rectangle, a half-strip) can be obtained by the variables separation method. Let us explain this with examples.

Example. The problem reduces to solving the equation

$$
\nabla \mathrm{u}=-\frac{q}{k}, \text { under the conditions } \begin{aligned}
& \left.u\right|_{x=0} ;\left.u_{x}\right|_{x=a}=0 ; \\
& \left.u\right|_{y=0} ;\left.u_{y}\right|_{y=b}=0 .^{\prime}
\end{aligned}
$$

where $k$ is the coefficient of internal thermal conductivity. This problem is solved by the Fourier method for a nonhomogeneous equation with homogeneous boundary conditions.

Setting up a problem

How do you understand (how can you explain) the results obtained? Can you verify the correctness of such results?

Putting forward the hypothesis

Solving this problem, some students immediately tried using the Fourier method for the Laplace equation in a ring, in a circle, outside the circle, in a circular sector.

In our experiment, there were students who at first did not have a clear understanding of how to use the Fourier method. Looking at the statement, they had a question: "How were such results obtained when solving boundary value problems in a circle, outside the circle, in a circular sector, in a ring? Does one have to move from the Cartesian coordinates $(x, y)$ to polar coordinates $(r, \varphi)$ according to formulas: $x=r \cos \varphi, y=r \sin \varphi$.

They formulate a problem as: how, using the Fourier method, can one obtain a solution for the Laplace equation in a ring, in a circle, outside the circle, in a circular sector?

Proving the hypothesis

Next, they check the Fourier method using formulas and obtain results.

After this, the Laplace equation has the form:

$$
r^{2} u_{r r}+r u_{r}+u_{\varphi \varphi}=0
$$

where $u(r, \varphi)=u(r, \varphi+2 \pi)$. 
The solution of the Laplace equation in a ring

$$
u(r, \varphi)=\alpha_{0} \ln r+\beta_{0}+\sum_{k=1}^{\infty}\left(\alpha_{k} r^{k}+\alpha_{-k} r^{-k}\right) \cos k \varphi+\left(\beta_{k} r^{k}+\beta_{-k} r^{-k}\right) \sin k \varphi .
$$

The solution of the Laplace equation in a circle is as follows:

$$
u(r, \varphi)=C+\sum_{k=1}^{\infty} r^{k}\left(A_{k} \operatorname{cosk} \varphi+B_{k} \operatorname{sink} \varphi\right)
$$

The solution of the Laplace equation outside the circle has the form:

$$
u(r, \varphi)=C+\sum_{k=1}^{\infty} r^{-k}\left(A_{k} \cos k \varphi+B_{k} \sin k \varphi\right)
$$

This task allowed students to develop a more conscious approach to problem solving that requires applying the Fourier method for the Laplace equation in a ring, in a circle, outside the circle, in a circular sector (Sadybekov et al., 2014).

During the pedagogical experiment, when developing the elective course, we used the computer as a tool for creating dynamic images (animation) to illustrate mathematical concepts or problem statement, and to perform laborious calculations, which allowed students to focus on the object under study and not waste their time doing operations well known to them, or completing the calculation tables, etc.

In teaching the mathematical physics equations, among various mathematical software, we mainly used the Maple (Goloskokov, 2014). It was used to perform cumbersome calculations, plotting the functions of one or two variables, observing the change in the form of the graph, depending on the value of the parameter.

Computers were used for teaching various topics of mathematical physics equations: "The Fourier method (homogeneous hyperbolic and parabolic equations with homogeneous boundary conditions) for the equations of string vibrations and for a heat equation", "Homogeneous equation", "Free oscillations", etc.

Problem 3.

Mixed problems for the heat equation

Let us consider the mixed problem for the heat equation in the intervals [0, $\mathrm{p}]$.

Setting up a problem

To solve the problem, you can use the resources of the Maple software. Formulate a hypothesis.

Putting forward the hypothesis

Students clarify the problem: under what conditions

$$
\begin{aligned}
& u_{t t}=a^{2} u_{x x}, 0<x<p, t>0 \\
& \mathrm{u}(0, \mathrm{t})=0, \mathrm{u}(\mathrm{p}, \mathrm{t})=0, \mathrm{t}>0
\end{aligned}
$$

initial condition

$$
\mathrm{u}(\mathrm{x}, 0)=\mathrm{f}(x), 0<\mathrm{x}<\mathrm{p}
$$

equals the equation.

\section{Proving the hypothesis}

To carry out the work associated with putting forward the hypothesis, the students were divided into two groups. The students in the first group proposed the hypothesis after studying the expression, and calculated that

$$
u(x, t)=\sum_{k=1}^{\infty} c_{k} e^{-(k \pi a / p)^{2}} \sin (k \pi x / p)
$$

equals

$$
c_{k}=\frac{2}{p} \int_{0}^{p} f(x) \sin (k \pi x / p) d x
$$

The second group, using the experimental results, solved the problem using the Maple software.

Now, let us consider the solution obtained using Maple. Let the function $w(x, t)$ be a solution of this problem. Let us introduce this function 
$>$ restart:

$w:=(k, x, t)->\exp \left(-k^{\wedge} 2^{*} \mathrm{Pi}^{\wedge} 2^{*}\right.$ alpha^ $\left.2 * t / p^{\wedge} 2\right) * \sin \left(k^{*} P i^{*} x / p\right)$;

$$
w:=(k, x, t) \rightarrow \mathbf{e}^{\left(-\frac{k^{2} \pi^{2} \alpha^{2} t}{p^{2}}\right)} \sin \left(\frac{k \pi x}{p}\right)
$$

The Fourier coefficients are

$>c:=k \rightarrow 2 / p^{*} \operatorname{int}\left(f(x) * \sin \left(k^{*} \mathrm{Pi}^{*} \mathrm{x} / \mathrm{p}\right), \mathrm{x}=0 . \mathrm{p}\right)$;

$$
c:=k \rightarrow \frac{2}{p} \int_{0}^{p} f(x) \sin \left(\frac{k \pi x}{p}\right) d x
$$

The approximate solution of the problem corresponds to the initial $n$ sum and is estimated as:

$>\mathrm{u}:=(\mathrm{n}, \mathrm{x}, \mathrm{t}) \rightarrow \operatorname{sum}(\mathrm{c}(\mathrm{k}) * \mathrm{w}(\mathrm{k}, \mathrm{x}, \mathrm{t}), \mathrm{k}=1 \ldots \mathrm{n})$;

$$
u:=(n, x, t) \rightarrow \sum_{k=1}^{n} \mathrm{c}(k) \mathrm{w}(k, x, t)
$$

Let us assign a value to the parameters

$$
\begin{array}{cc}
>\text { alpha }:=1 ; p:=50 ; & \alpha:=1 \\
& p:=50 \\
>f:=x->25 ; & f:=x \rightarrow 25
\end{array}
$$

Using the $\mathrm{n}$ value of the series, we can find temperature $u$ at the point $x$ at time $t$.

For instance, if the values are $\mathrm{x}=15 ; \mathrm{t}=100 ; \mathrm{n}=10$ then

$$
\begin{aligned}
& >\mathrm{u}(10,15,100): \\
& >\operatorname{evalf}(\mathrm{u}(10,15,100)) \text {; }
\end{aligned}
$$

\subsection{4}

Then we get a three-dimensional graph of the temperature distribution on the computer screen (Figure 2).

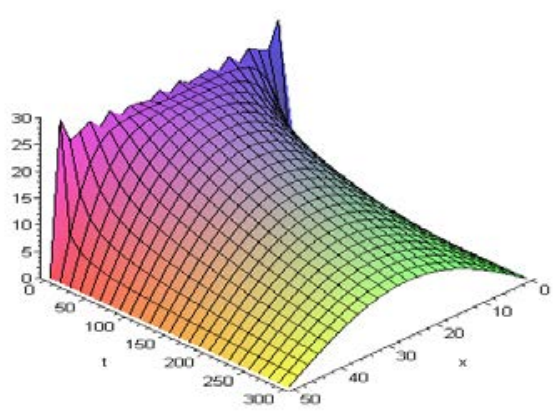

Figure 2. Three-dimensional graph of temperature distribution

$$
>\operatorname{plot} 3 d(u(20, x, t), x=0.50, t=0 . .300, v i e w=0 . .30 \text {, axes=FRAMED, style }=\text { PATCH }) \text {; }
$$

After this, the subgroups changed, and it was the first that clarified the proposed hypothesis, using the resources of the Maple software. Using Maple, students not only calculated and obtained the graph of the temperature distribution, but also put forward a hypothesis about the intervals.

Working on this problem, the students could apply their knowledge of Maths, creative skills and imagination.

When performing such tasks, students are given a considerable degree of independence, whereas a teacher would have to present specially formulated tasks, manage and correct students' work. If such tasks cover a significant part of the course content or some theoretical area, each group of students receives a detailed work plan 
indicating the issues to be solved. Performing such work, problems are formulated, hypotheses are put forward, and students try to prove them.

The practical work on the introduction of the methodology developed by us, which aims to develop students' search and research skills when mastering the mathematical physics equations proved that it enables solving the whole range of tasks:

- increasing the general level of students' math knowledge, in particular that related to the mathematical physics equations;

- motivating students, and developing their cognitive interest;

- providing prospective teachers with mathematical and methodological materials, which they can use later teaching their students;

- introducing students to a new type of activity dealing with search and research;

- developing students' communication skills, productive work in groups and with a teacher, their readiness to air their ideas and to defend their hypotheses.

Making students' activities more similar to the creative work of a teacher, we can increase its connection with future professional activities that require students to be able to put forward problems, make assumptions, ask questions, solve problems, etc.

\section{Stages of the Development of Search and Research Skills of Prospective Math Teachers}

The ascertaining stage of the experiment was conducted in 2015-2016. At this stage, the following tasks were to be solved:

1. To identify the conditions (specific features of the learning process) that contribute to students' interest in research activities.

2. To determine what educational skills first-year students have. To collect information on their expectations from study in a teacher training university, whether university instruction corresponds to their expectations.

To achieve these goals, the authors studied psychological, pedagogical and methodical papers on the relevant issues, as well as normative documents on education. Other methods included surveys, interviews and observations.

To identify conditions facilitating the formation of research skills, we surveyed the pupils who participated in scientific and practical conferences. It should be noted that such a choice of participants in the survey was not accidental, since it is these students that represent the most active, talented and creative part of the youth, and they are to become university students, prospective researchers, and innovators that the modern society needs.

The search phase of the experiment was conducted in 2016-2017. It consisted of the following tasks:

- to clarify the content of such concepts as "search and research activities", "skills of search and research activities";

- to identify the main skills of students' search and research; to determine the composition and function of these skills in the learning process;

- to collect information on the ways of developing search and research skills when teaching the mathematical physics equations course to prospective math teachers, and how this should be accomplished;

- to develop a model of the development of search and research skills of prospective math teachers in the mathematical physics equations course;

- to create an elective course on the mathematical physics equations, to compile a system of problems and tasks for them, which makes it possible to conduct the learning process aimed at developing the students' search and research skills.

- to determine the most appropriate means, methods and forms of training, to identify the conditions that contribute to the formation of search and research skills.

Solving the abovementioned tasks at this stage of the experiment, we analyzed publications on the research problem, monitored the process of teaching mathematics at the university, examined learning outcomes, and interviewed students.

Along with this, we introduced and tested the proposed model for the development of students' search and research skills. During the search experiment, the authors tested and adjusted the selected approaches to the development of students' search and research skills, as well as their relevance and the potential of introducing them into instruction. This work allowed us to establish that skills development should start before the students have their teaching internship and write their term papers, i.e. from the first year at university. Thus, it is viable to allocate extra time to studying the section "Mathematical physics equations" (the first section of the mathematical 
physics equations mastered by students). In our research, the main means of training was a set of special problems and tasks, with the elective course chosen as the most effective form of training.

In addition to that, this stage included studying general issues of an elective course management; the authors devised a set of problems and tasks for instruction aimed at developing students' search and research skills.

\section{Conditions Ensuring the Effective Development of Search and Research Skills}

The conditions ensuring the effective development of search and research skills of prospective math teachers are:

- Organizational: They are selected according to external elements, i.e. they depend on mastering the subject content that enables their development, the number of classes (in accord with the curriculum and the schedule), available teaching aids, the resources of the educational institution, group size, and their overall level.

- Psychological and pedagogical: They affect the skills development "from within". The internal ones are the individual and age specifics of students, their motivation, responsibility, independence. Some others on this list are: the individual characteristics of teachers, their professionalism, and teaching means used. Skills development also requires friendly atmosphere, understanding and trust (so that students feel free to express their own opinion, defend their own position, listen to the arguments of others).

In line with the ideas of the step-by-step formation of mental actions and concepts chosen as the theoretical basis of our research, search and research skills should be developed systematically, stage by stage. The development stages imply a preliminary analysis of the skills composition in order to determine whether some skills make up a part of others and to determine the possible levels of complexity, depending on the number and frequency of structural actions; that is, identifying sub-skills within skills. This condition is fulfilled by some specific methods. The step-by-step formation of skills implies going through the selected stages, regardless of the features of the skill itself - some general stages.

\section{Experimental Verification of Search and Research Skills Development by Prospective Math Teachers}

To test the formulated hypothesis, we conducted a pedagogical experiment.

The educational stage included the experimental testing of the research hypothesis by means of all didactic materials that had been developed, adjusted and described above, and analysis and summarization of the study findings. The experiment was held at the South Kazakhstan State Pedagogical University, M. Auezov SouthKazakhstan State University, Kh. A. Yasavi International Kazakh-Turkish University among math students (20152016). The experiment involved the total of 232 students.

The experiment included the following procedures: 1) introductory test (placement test); 2) conducting classes (in the control and experimental groups, with traditional instruction and the developed methodology, respectively); 3) diagnostic test.

To describe the main research findings in the thesis, we chose two groups of math students: control group 6 (CG) and experimental group 7 (EG). Both groups were studying the topics within the established curriculum. In the control group, instruction was done using traditional methods, and in the experimental group experimental training was introduced, i.e. a different methodology was used to teach the material within the elective mathematical physics equations course. Classes in the experimental group were conducted by the authors of this paper.

At the first stage of the experiment, starting to work with first-year students, we tried to determine the level of their learning skills, and whether the chosen groups are comparable after these parameters.

Before the beginning of the experimental teaching, we tested both groups (CG and EG) using the subtests based on the teaching and methodological recommendations of J. M. Francisco to determine cognitive skills: analogy, generalization, classification (2013).

The obtained values of sample means and variances indicate that the level of development of cognitive skills among students of these groups (CG and EG) is practically the same (Table 1). Thus, the obtained results (whether the students in each group have the same level of cognitive skills), and the fact that the groups were randomly formed prove that the initial parameters of the students' skills development were the same. 
Table 1. Indicators of the development of cognitive skills

\begin{tabular}{ccccccc}
\hline & \multicolumn{3}{c}{ Cognitive skills } \\
\cline { 2 - 7 } Statistical values & \multicolumn{2}{c}{ Analogy } & \multicolumn{2}{c}{ Generalization } & \multicolumn{2}{c}{ Classification } \\
\cline { 2 - 8 } & CG & EG & CG & EG & CG & EG \\
\hline $\bar{x}$ & 3.1 & 3.4 & 10.6 & 11.1 & 6.7 & 6.9 \\
\hline$\overline{s^{2}}$ & 1.5 & 1.7 & 3.1 & 3.6 & 1.7 & 1.9 \\
\hline
\end{tabular}

To prove the hypothesis of the study, we observed and surveyed students, as well as studied their works. To enable an objective assessment of the effectiveness of the developed methodology aimed at the development of main search and research skills of students, we conducted tests before and after the experimental training. These included tasks for which it was necessary to use one of the selected research skills.

The first test, which determined the initial level of search and research skills development, contained six tasks from the algebra course, and introduction to analysis. The second test was conducted after the experiment and focused on the mathematical physics equations, which also consisted of six problems. The solution of each problem demonstrated the development of each of the three main search and research skills of prospective math teachers. Below, one of these tests is presented:

\section{Test 1}

1. Bring the equation into the canonical form

$$
u_{x x}+4 u_{x y}+13 u_{y y}+3 u_{x}+24 u_{y}-9 u+9(x+y)=0
$$

2. Find the general solution of the partial differential equation:

$$
v_{\xi \eta}-2 v_{\xi}+\frac{1}{2} \eta e^{\frac{1}{2} \xi+2 \eta}=0 .
$$

3. Find a solution that satisfies the Cauchy conditions:

$$
\begin{gathered}
u(x, y)=\left[f_{1}(y-\sin x-x)+f_{2}(y-\sin x+x)\right] e^{\frac{y-\sin x-x}{2}}, \\
\left.u\right|_{y=\sin x}=\cos x,\left.u_{y}\right|_{y=\sin x}=\sin x .
\end{gathered}
$$

4. Solve the following problem using the Fourier method:

$$
\begin{gathered}
u_{t t}=u_{x x}+2 u_{t}=4 x+8 e^{t} \cos x,\left(0<x<\frac{\pi}{2}\right) ; \\
\left.u_{x}\right|_{x=0}=2 t ;\left.u\right|_{t=0}=\cos x ;\left.u_{t}\right|_{t=0}=2 x .
\end{gathered}
$$

5. Solve the following mixed problem:

$$
\begin{gathered}
u_{t t}=u_{x x}+4 u+2 \sin ^{2} x ;(0<x<\pi) \\
\left.u_{x}\right|_{x=0}=\left.u\right|_{x=\pi} ;\left.u\right|_{t=0}=\left.u_{t}\right|_{t=0}=0 .
\end{gathered}
$$

6. Find a harmonic function inside a circle of radius $R$ with the center at the origin that satisfies the following boundary condition: $\left.u\right|_{r=\varphi}=f(\varphi)$.

The answers to each problem were marked with 0-4 points. The points scored allowed us to determine the level of corresponding search and research skills shown by students ( 0 as the smallest value, 4 - the largest).

The initial statistical processing of the experimental results included such numerical characteristics of the general population (points scored by students for each of the main skills) as a sample mean and sample variance. We applied this statistics to describe the current level of main research skills in each of the student groups examined, and then, comparing the values of the sample mean, assessed the relative degree of development of the corresponding skills shown by the representatives of each group. Being a statistical variable, sample variance describes the degree to which the particular values deviate from the average value in a given sample. The values of sample means and sample variances obtained for the considered student groups after conducting the tests are presented in Table 2. 
Table 2. Test results in CG and EG groups

\begin{tabular}{cccccccc}
\hline & & \multicolumn{2}{c}{$\begin{array}{c}\text { The skill of setting up a } \\
\text { problem }\end{array}$} & $\begin{array}{c}\text { The skill of purring forward } \\
\text { a hypothesis }\end{array}$ & $\begin{array}{c}\text { The skill of proving a } \\
\text { hypothesis }\end{array}$ \\
\cline { 3 - 9 } & $\bar{x}$ & $\overline{s^{2}}$ & $\bar{x}$ & $\overline{s^{2}}$ & $\bar{x}$ & $\overline{s^{2}}$ \\
\hline \multirow{2}{*}{ CG } & Before the experiment & 0.94 & 0.75 & 1.71 & 0.70 & 0.98 & 0.89 \\
\cline { 2 - 9 } & After the experiment & 1.17 & 1.34 & 2.03 & 1.93 & 1.53 & 3.02 \\
\hline \multirow{2}{*}{ EG } & Before the experiment & 1.07 & 0.77 & 1.68 & 0.6 & 0.98 & 0.68 \\
\cline { 2 - 8 } & After the experiment & 1.94 & 1.15 & 2.64 & 0.88 & 2.17 & 1.1 \\
\hline
\end{tabular}

The values of sample means and variances obtained at the first stage indicate that the students of both groups (CG and EG) had an almost identical level of development of skills under study. The results of the second test, conducted after the end of the experimental instruction, demonstrate a significant difference between them. These data also indicate a positive dynamics for the development of each of the main search and research skills shown by students who were trained according to the proposed methodology (EG). The levels of each search and research skill at the beginning and at the end of the educational stage of the experiment in CG and EG are presented in the charts (Figures 3 and 4).

Comparing the average values from the samples of the experimental data (the level of each of the three search and research skills) at the beginning and at the end of the experiment in EG, we can note their significant difference. Using the secondary methods of statistical processing of experimental data (in particular, the method of comparison of sample mean values), we can establish the presence or absence of statistically significant differences between these average values, i.e. we check whether the proposed method of developing search and research is effective or not.

To determine whether the mean values differ significantly from each other, we used Student's t-test. Its main formula is as follows:

$$
t=\frac{\left|\overline{x_{1}}-\overline{x_{2}}\right|}{\sqrt{\left|m_{1}^{2}+m_{2}^{2}\right|}}
$$

Where $\overline{x_{1}}$ is the average value of the variable from the first data sample (at the beginning of the experiment); $\overline{x_{2}}$ is the value of the variable from the second data sample (at the end of the experiment); $m_{1}^{2}$ and $m_{2}^{2}$ are integrated indicators of deviations of the partial values of the two compared samples from their corresponding average values, which are calculated by formulas:

$$
m_{1}^{2}=\frac{S_{1}^{2}}{n_{1}} ; m_{2}^{2}=\frac{S_{2}^{2}}{n_{2}}
$$

Where $S_{1}^{2}$ is the sample variance of the first variable (from the first sample); $S_{2}^{2}$ is the sample variance of the first variable (from the second sample); $n_{1}$ is the number of students in the first sample, $n_{2}$ is the number of students in the second sample. In our case, the number of students at the beginning and the end of the experiment was the same.

Let us estimate indicators $t_{\mathrm{sp}}, t_{\mathrm{pfh}}, \mathrm{t}_{\mathrm{ph}}$ using the data obtained respectively to describe setting up a problem, putting forward a hypothesis, and proving a hypothesis.

$$
\mathrm{t}_{\mathrm{sp}}=\frac{|1.04-1.91|}{\sqrt{\frac{0.74}{13}+\frac{1.12}{13}}}=2.35, \mathrm{t}_{\mathrm{pfh}}=\frac{|1.65-2.61|}{\sqrt{\frac{0.57}{13}+\frac{0.85}{13}}}=2.66, \mathrm{t}_{\mathrm{ph}}=\frac{|0.96-2.13|}{\sqrt{\frac{0.65}{13}+\frac{1.07}{13}}}=3.22
$$

Let us compare these values with the critical value of Student's distribution, which depends on the degree of freedom that equals $\mathrm{f}=\mathrm{n} 1+\mathrm{n} 2-2=13+13-2=24$, and on the chosen probability of an admissible error (in our case it equals 0.01$)$. The value of Student's t-test is 2.31 . Thus, the differences are statistically significant $(p<0.05)$. The number of degrees of freedom $\mathrm{f}=24$. The critical value of the Student's t-test is 2.064, with the significance level a $=0.05$. Let us make sure that for a given number of degrees of freedom and a given probability of an admissible error, the values of $t$ must be no less than 2.064. In our calculations, these indicators exceed the corresponding critical value of Student's distribution (with $99 \%$ accuracy of calculation or the probability of an admissible error not exceeding $1 \%$ ). Since the probability of an acceptable error that is equal to or less than 0.01 is considered sufficient for a scientifically convincing conclusion, the main points of the hypothesis of the research formulated by us have been proven. Thus, in the course of the experiment, we established that the use of the proposed methodology helps develop the main search and research skills of prospective math teachers through the mathematical physics equations course.

Thus, the carried-out analysis and the results obtained clearly prove that the research objectives have been met and the goal has been reached. 


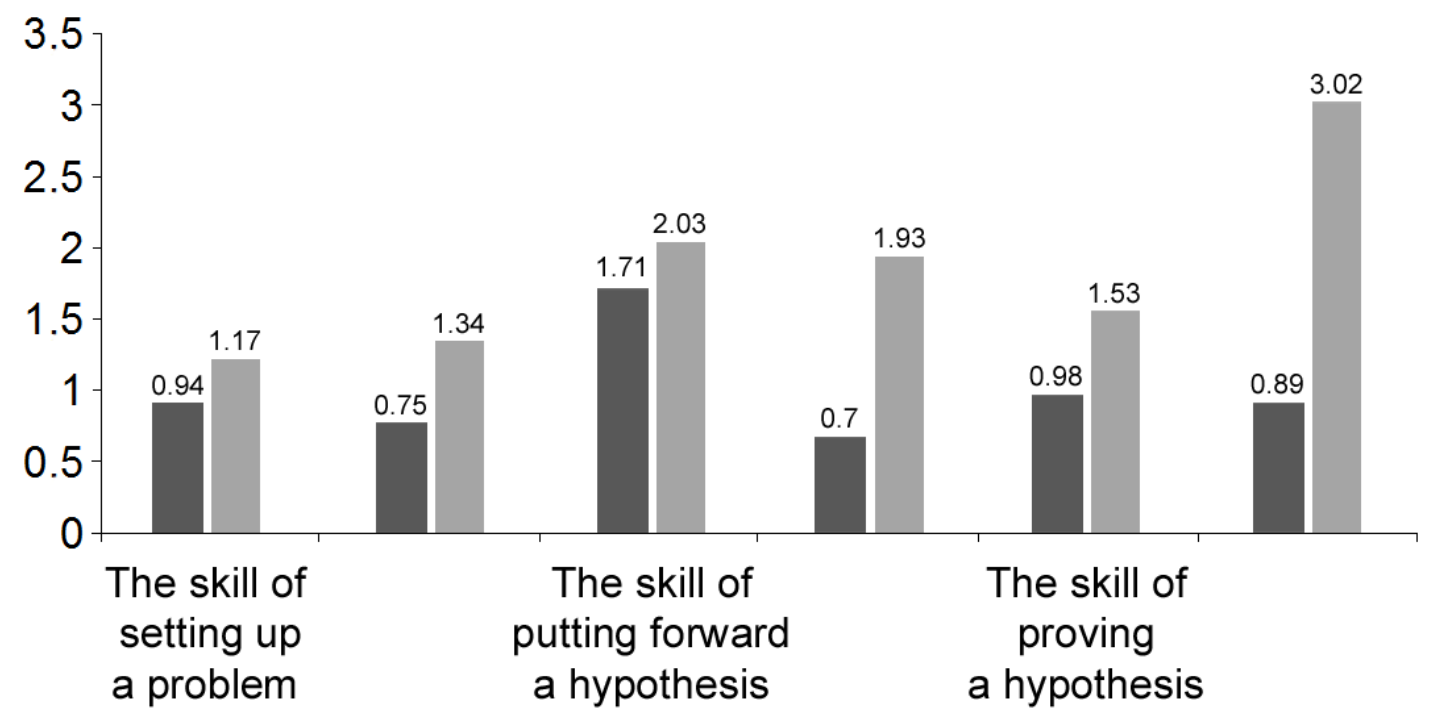

CG before the experiment

CG after the experiment

Figure 3. The level of development of the main search and research skills in the control group at the educational stage of the experiment

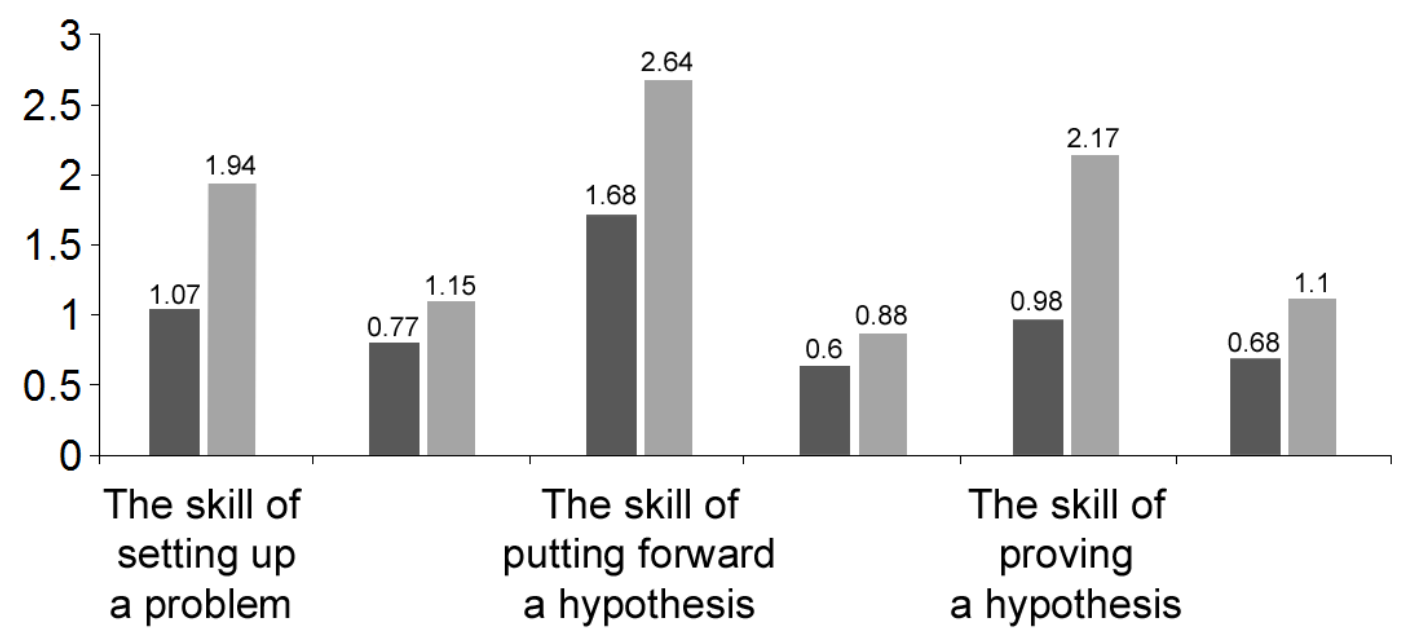

\section{EG before the experiment $\quad$ EG after the experiment}

Figure 4. The level of development of the main search and research skills in the experimental group at the educational stage of the experiment

\section{DISCUSSION}

Considering the prerequisites for the professional training of a prospective teacher, the authors name the transformation of the system of teachers' training that would enable the transition from the mass reproductive system of staff training to an individually tailored creative system of a prospective teacher of a certain subject. This new system should involve using active methods of professional training, flexible techniques of learning management in higher education, as well as independent research activity of the student.

I. S. Lerner proposes shifting the focus of teacher training to the development of a prospective teachers' inner world and their creativity. 
Another condition for the professional development of the would-be teacher, is the creation of professional development schools, seminars, and groups similar to classes, workshops, and studios in creative arts universities.

Improving the professional training of prospective teachers and updating the content and teaching technologies are the issues that are actively researched and discussed in theoretical works. Improvement of the professional training of would-be teachers requires, on the one hand, the use of IT, and on the other hand, effective teaching technologies and their application in the learning process (Usembayeva et al., 2015).

The general theory of activity states that activity is the basis of the learning process. Any activity has its own goals, conditions for their achievement, a specific process, structure and outcome.

Learning skills applied by students to search for information include: solving equations by non-conventional methods, solving the equations using symmetries that make up these equations.

To define the content of the concept "search and research skills" within the chosen area, we will analyze various interpretations of such concepts as: "search", "research", "research activity", "heuristic" and "heuristic activity".

Search is a goal-oriented activity. It is aimed at finding the principle, the logic of a problem solution that ultimately leads to obtaining the desired result.

According to the definition given by $\mathrm{Yu}$ A. Kuznetsova, search is a process of setting up and solving mathematical problem-based situations (situations posing intellectual difficulties).

Research is one of cognitive activity types; it is the process of developing new knowledge (Kuznetsov, 2000).

Student research is a study that is characterized by two criteria: 1) the investigated problem is put forward according to didactic goals; 2) the research itself, as a teaching method, bears a dual educational character: it teaches certain content and develops some elements of research activity.

Research is an activity connected with finding an answer to a creative, research problem with a previously unknown solution, and which includes main characteristic stages of research in the scientific field (Otten, 2010).

A. Khutorskoy defines heuristics as an area of human activity that implies the creation of a subjectively or objectively new and significant product (2003).

Heuristic activity has the following characteristic features: premeditation, a teacher primarily using tools of indirect and advanced management, a problem-based situation, an educational and creative task, maximum learner's autonomy, the subjective novelty and originality of the outcome, creation of a new product as a result of the activity, dominance of intuitive methods of activity (Chabalengula et al., 2012).

In this paper, we define search and research skills as a system of actions aimed at solving problem-based tasks and presented in the form of recommendations, prescriptions on using this or that mental operation (Savelsbergh et al., 2016). The development of search and research skills of would-be math teachers is understood as a process of a gradual delegation of an element of a given skill to a student to accomplish it independently without any side interventions.

\section{CONCLUSION}

By the final stage of the research, we met all objectives, the proposed hypothesis was fully proven, and the following results and conclusions were obtained.

1. The theoretical analysis of psychological and pedagogical papers allowed us to generalize the ideas on productive activity types related to students' search and research skills.

2. We define the search and research skills as a system of actions performed in a certain order, in the framework of research activities aimed at solving problem-based tasks and presented in the form of recommendations, instructions on the use of one or another mental operation. Among these, we singled out three main skills: the skill of setting up a problem, the skill of putting forward a hypothesis, the skill of proving/refuting a hypothesis. Later, we analyzed the main stages of certain types of creative activities according to these main skills.

3. We identified the types of tasks that ensure the most effective development of a particular search and research skill.

In accordance with the types of tasks established by us, we devised a set of problems to develop main search and research skills. These are generalization problems, experimental problems, problems with parameters, and applied problems.

4. The elective course "Methodology of managing students' search and research activities when teaching a course on mathematical physics equations" that included applied problems and the Maple mathematical software was considered one of the main forms of instruction aiming at the development of search and research skills of students. Within this course, the skills development is facilitated by doing a set of experimental problems reflecting the specific features of mathematical physics equations, and the combination of various work modes: collective, group, pair, and individual work. 
5. We have experimentally proven the effectiveness of the developed methodology for the development of search and research skills of prospective math teachers in the mathematical physics equations course.

The obtained scientific findings can be used as a theoretical basis for further research on ways of developing search and research skills of students when studying the mathematical physics equations and other mathematics subjects.

\section{REFERENCES}

Abdolhossini, A. (2012). The effects of cognitive and meta-cognitive methods of teaching mathematics. ProcediaSocial and Behavioral Sciences, 46, 5894-5899. doi:10.1016/j.sbspro.2012.06.535

Abylkasymova, A. E., Nurmukhamedova, Zh. M., Nurbaeva, D. M., \& Zhumalieva, L. D. (2016). “The Turkish Vector" influence on teaching the exact disciplines in modern educational system of Kazakhstan: On the example of teaching algebra and mathematics. Global Journal of Pure and Applied Mathematics, 12(4), 34813491.

Chabalengula, V.M., Mumba, F., \& Mbewe, S. (2012). How pre-service teachers understand and perform science process skills. Eurasia Journal of Mathematics, Science E Technology Education, 8(3), 167-176.

Dinet, J., Chevalier, A., \& Tricot, A. (2012). Information search activity: An overview. Revue Européenne de Psychologie Appliquée/European Review of Applied Psychology, 62(2), 49-62. doi:10.1016/j.erap.2012.03.004

Francisco, J. M. (2013). Learning in collaborative settings: Students building on each other's ideas to promote their mathematical understanding, Educational Studies in Mathematics, 82, 417-438.

Goloskokov, D. P. (2014). Mathematical physics equations. Solving problems with the Maple software. Textbook for high schools. St. Petersburg: Piter.

Gusev, V. A. (2003). Psychological and pedagogical foundations of teaching mathematics. Moscow: Verbum-M Publishing house; Academy.

Intaros, P., Inprasitha, M., \& Srisawadi, N. (2014). Students' problem solving strategies in problem solvingmathematics classroom. Procedia-Social and Behavioral Sciences, 116, 4119-4123. doi:10.1016/j.sbspro.2014.01.901

Isoda, M. (2010). Lesson study: Problem solving approaches in mathematics education as a Japanese Experience. Procedia-Social and Behavioral Sciences, 8, 17-27. doi:10.1016/j.sbspro.2010.12.003

Khutorskoy, A. V. (2003). Didactic heuristics. Theory and technology of creative teaching. Moscow: Moscow State University Publishing House.

Kuznetsov, S. A. (Ed.). (2000). Great Dictionary of the Russian language. St. Petersburg: Noprint.

Muratbekova, M. A., Shinaliyev, K. M., \& Turmetov, B. K. (2014). On solvability of a nonlocal problem for the Laplace equation with the fractional-order boundary operator. Boundary Value Problem, 2014(1), 29. doi:10.1186/1687-2770-2014-29

Otten, S. (2010). Conclusions within mathematical task enactments: A new phase of analysis. In P. Brosnan, D. B. Erchick \& L. Flevares (Eds.): Proceedings of the 32nd annual meeting of the North American Chapter of the International Group for the Psychology of Mathematics Education (661-669). Columbus, OH: The Ohio State University.

Rezat, S., \& Rezat, S. (2017). Subject-specific genres and genre awareness in integrated mathematics and language teaching. Eurasia Journal of Mathematics, Science and Technology Education, 3585-3606. doi: 10.12973/eurasia.2017.00805a

Sadybekov, M. A., Turmetov, B. Kh., \& Muratbekova, M. A. (2014). On solvability of some nonlocal boundary value problems with the Hadamard boundary operator. AIP Conference Proceedings, 1611, 266-270. doi:10.1063/1.4893845

Savelsbergh, E. R., Prins, G. T., Rietbergen, Ch., Fechner, S., Vaessen, B. E., Draijer, J. M., \& Bakker, A. (2016). Effects of innovative science and mathematics teaching on student attitudes and achievement: A meta-analytic study. Educational Research Review, 19, 158-172. doi:10.1016/j.edurev.2016.07.003

Simon, M. (2014). Hypothetical Learning Trajectories in Mathematics Education. In S. Leman (Ed.), Encyclopedia of Mathematics Education, pp. 272-275. The Netherlands: Springer.

Usembayeva, I. B., Ramankulov, Sh. J., Berdi D. K., Saparbekova G. A., \& Ualikhanova, B. S. (2015). Procedure of Implementation the Applied Orientation of Future Teachers' Training Using ICT. American Journal of Applied Sciences, 12(9), 636-643. doi:10.3844/ajassp.2015.636.643

\section{http://www.ejmste.com}

